\title{
Research on a Mixed Culture Technique of the White Rot Fungi Effect of Extracellular Lignin Peroxidase on Lignite Liquefaction
}

\author{
Kaiyi Shi ${ }^{1 *}$ and Jun Wang ${ }^{2}$ \\ ${ }^{1}$ School of Chemistry and Materials Engineering, Liupanshui Normal University, Liupanshui, China, ${ }^{2}$ College of Engineering, \\ University of Wisconsin-Madison, Madison, WI, United States
}

OPEN ACCESS

Edited by:

Kalpit V. Shah

RMIT University, Australia

Reviewed by:

Ganesh Veluswamy,

RMIT University, Australia

Yashoda Malgar Puttaiahgowda,

Manipal Institute of Technology, India

${ }^{*}$ Correspondence:

Kaiyi Shi

andrewshikai@126.com

Specialty section:

This article was submitted to Advanced Fossil Fuel Technologies,

a section of the journal

Frontiers in Energy Research

Received: 21 December 2018 Accepted: 06 November 2019 Published: 10 December 2019

Citation:

Shi K and Wang J (2019) Research on

a Mixed Culture Technique of the White Rot Fungi Effect of Extracellular

Lignin Peroxidase on Lignite

Liquefaction.

Front. Energy Res. 7:133

doi: 10.3389/fenrg.2019.00133
White rot fungi mixed culture technology was applied in order to improve the efficiency of lignite liquefaction. In this paper, 15 fungi were used to liquefy Zhaotong lignite. The results showed that there was a good linear relationship between the liquefaction effect and lignin peroxidase (LiP). Since the low activity of LiP is the barrier in real practice, five strains with the highest LiP activity for a combinatorial culture suggested that a mixed strains culture is an effective way to improve LiP activity and the liquefaction effect, and the average enzyme activity was $76.28 \mathrm{U} / \mathrm{L}$. The single strain, however, was only 19.24 $\mathrm{U} / \mathrm{L}$. Among 10 mixed culture strains, four of them showed obvious synergy, and the one with maximum enzyme activity had increased by 6.7 times its original size. The analysis of lignite and liquefaction products using ${ }^{13} \mathrm{C}$ NMR showed that the aromatic carbon $\left(f_{\mathrm{a}}\right)$ decreased while the phenol or aromatic ether carbon $\left(f_{\mathrm{a}}^{\mathrm{P}}\right)$ and oxygen-linked fatty carbon $\left(f_{\text {al }}^{\mathrm{O}}\right)$ increased, which proved that LiP had undergone ring-opening, oxidation, and other reactions during lignite liquefaction.

\section{Keywords: lignite, white rot fungi, lignin peroxidase (LiP), mixed culture, liquefaction rate}

\section{INTRODUCTION}

Coal is one of the main energy sources in China. According to BP's World Energy Statistics Report in June 2017, the total coal consumption of China was 1,685.7 million tons of oil equivalent in 2016, which accounts for 46.1 and $61.8 \%$ of the world's coal consumption and primary energy consumption, respectively (BP Statistical Review, 2017). The reserve of lignite resources contains over 130 billion tons of coal, accounting for $\sim 13 \%$ of the national coal reserves (Han et al., 2016). However, lignite has obvious disadvantages such as high moisture content, high ash content, high porosity, and low calorific value. Therefore, it is not suitable for direct use. Normally, lignite is burnt to generate electricity, however its use in electricity generation has caused issues; environmental issues such as haze are becoming increasingly prominent during the combustion process (Zhang et al., 2015), resulting in many lignite power plants being shut down.

The chemical process of turning lignite into a high value chemical compounds is a promising method; however, these conversion processes have to be carried out under high temperature and high pressure, and they generate hazardous secondary compounds during the process (Choudhary et al., 2016; Barbara, 2017). Compared to chemical treatment, the microbial liquefaction of lignite is an environmentally friendly, mild reaction condition with no secondary pollution method, and it is therefore attracting the interest of researchers (Jiang et al., 2013; Romanowska et al., 2015; Shi et al., 2015; David et al., 2017; Luo et al., 2017). 
The reason why lignite can be degraded by microorganisms is that coal is a complex macromolecular polymer consisting of large polycyclic aromatic clusters of several rings (Hayatsu et al., 1979; Hölker et al., 1999). It is produced by ancient plants in different natural environments through a series of biological, chemical, and physical chemical effects. The biodegradation of coal is a process that uses oxidative depolymerization combined with the participation of microorganisms or bioactive enzymes; it can be considered the reverse process of coal formation. Many studies have reported that certain fungi (most representative is white rot fungi) can secrete lignin-degrading enzymes such as lignin peroxidase (LiP, EC 1.11.1.14), manganese peroxidase (MnP, EC 1.11.1.13), laccase (Lac, EC 1.10.3.2), and hydrolase (Mäkelä et al., 2013; Barrasa et al., 2014) to degrade lignin. Since Coal is generated from plants, low-rank coal contains many lignin structures, such as lignite. There are many side chains and bridges in coal molecules, and the content of reactive functional groups is high, which make it very easily degraded by microorganisms (Hölker et al., 1999).

Lignin peroxidase $(\mathrm{LiP})$ is one of the most popular white rot fungi extracellular enzymes studies. LiP was first discovered in Phanerochaete chrysosporium (Tien and Kirk, 1983), and various isozymes of $\mathrm{LiP}$ are also present in other white rot fungi. The LiP isozyme is a type of glycoprotein with a molecular weight of $38-46 \mathrm{kDa}$, an isoelectric point of 3.2-4.0, an optimal enzyme activity temperature of $35-55^{\circ} \mathrm{C}$, and an optimum $\mathrm{pH}$ of $2-$ 5 (Asgher et al., 2006). Each mol of protein contains $1 \mathrm{~mol}$ of iron-protoporphyrin IX. The redox potential of LiP is $1.5 \mathrm{~V}$. In the presence of $\mathrm{H}_{2} \mathrm{O}_{2}, \mathrm{LiP}$ can oxidize and decompose aromatic polymers, which are considered to be one of the key enzymes for lignin degradation. LiP contains a series of isozymes including $\mathrm{Fe}^{3+}$, porphyrin rings, and heme cofactors. Tien and Kirk (1988) believed that LiP can make use of $\mathrm{H}_{2} \mathrm{O}_{2}$ and organic peroxides to catalyze a series of substrates, and its catalytic action is non-specific. Haemmerli et al. (1986) and Hammel et al. (1986) found that LiP has a wide range of substrates, including phenolic and non-phenolic aromatic compounds, which can oxidize substrates such as lignin monomers, disomics, triads, and polycyclic aromatic hydrocarbons. The structural units of lignin are mainly linked by ether bonds $(\beta-\mathrm{O}-4)$ and carbon-carbon bonds (C-C). LiP degrades lignin by catalyzing the $\mathrm{C}_{\alpha}-\mathrm{C}_{\beta}$ chain of the lignin side chain (Hammel et al., 1993).

The main types of reaction catalyzed by LiP include: (1) C-C fracture, including both ring opening and side chain fracture; (2) demethylation, methoxy; (3) benzyl alcohol; and (4) hydroxylation, among others (Haemmerli et al., 1986; Hammel et al., 1986; Tien and Kirk, 1988).

Studies found that strains play an important role in the degradation process of lignite, and the performance of strains determines the success or failure of microbial liquefaction. For a long time, scholars in China and other countries have made great achievements in strain screening, domestication, and identification (Cohen and Gabriele, 1982; Maka et al., 1989; Bublitz et al., 1994; Gokcay et al., 2001). Nevertheless, the low activity of strains, long liquefaction period, and low liquefaction efficiency are still the most intractable technical problems in the liquefaction of coal microorganisms, which restricts the further development of coal microbial liquefaction technology. It has been proved that no liquefaction of macromolecules by microorganisms is performed by absolutely single microorganisms. Instead, the interactions and interrelationships between various microorganisms in the mixed strains liquefaction system have significant effects on biological liquefaction.

The co-cultivation of mixed strains has been applied to the degradation of lignin and the synthesis of natural products. Wen et al. (2005) demonstrated that Aspergillus phoenicis and Trichoderma reesei could be co-cultured to produce $\beta$ glucosidase and cellulase. Trichoderma reesei was co-cultured with Coprinus comatus to improve laccase activity, and the results showed that the highest laccase activity from the co-culture was 2.6-fold greater than that of the C. comatus monoculture and reached its peak 3 days earlier (Ma and Ruan, 2015). Three white rot fungi, Dichomitus squalens, Trametes versicolor, and Pleurotus ostreatus, were chosen as laccase production fungi to reveal the differential levels of intracellular metabolites when fungal mycelia interact with each other. Chuanren et al. (2009) took Trametes cinnabarina, $P$. ostreatus, and P. chrysosporium as mixed culture examples of white rot fungi. By measuring the activity of ligninase, it was found that the compound strains produced higher enzyme activity than single strains.

However, there has been few open public reports on the liquefaction of lignite by mixed strains. Therefore, based on strain screening, this article compared the relationship between the activity and liquefaction effect of extracellular lignin peroxidase secreted by single strains and mixed strains. As a result, the role of depolymerization of peroxidase in lignite lignin was expounded based on the changes of the macromolecular structure of lignite before and after depolymerization, which can lay the foundation for elaborating on the bio-liquefaction mechanism of lignite.

\section{EXPERIMENTAL MATERIALS AND METHODS}

\section{Coal and Its Pretreatment}

Coal samples used in this study were collected from the Zhaotong opencast lignite mine. The coal was first ground to below $0.2 \mathrm{~mm}$, and then, through proximate analysis, it was found that the water content of Zhaotong lignite reaches $35.56 \%$, and the ash content is $27.51 \%$. In order to improve its liquefaction efficiency, oxidation pretreatment was carried out. Nitric acid oxidation was generally considered as one of the most effective and commonly used methods (Machnikowska et al., 2002). The concentration of nitric acid was $8 \mathrm{~mol} / \mathrm{L}$ and mixed with the coal particles in a ratio of $1 \mathrm{~g}: 2 \mathrm{~mL}$. After oxidation for $48 \mathrm{~h}$, the oxidized coal was washed with deionized water until the $\mathrm{pH}$ of the washing solution was $>5.5$.

\section{Microorganism}

There were two major sources of experimental microorganisms. First, there were two white rot fungi, T. versicolor (CGMCC NO 5.960) and Schizophyllum commune (CGMCC NO. 5.390), which were purchased from the Institute of Microbiology at the Chinese Academy of Sciences (IMCAS) and used after activation 
in PDA culture (boiled potato $200 \mathrm{~g} / \mathrm{L}$, glucose $20 \mathrm{~g} / \mathrm{L}$ ). Second, there were the microorganisms screened from the surrounding soil, pit water, and decay wood in the Zhaotong open lignite mine area. The screening method was based on existing research results (Sridevi and Charya, 2011), and the selected bacteria, actinomycetes, and fungi were further separated and purified. The result showed that Zhaotong nitric acid pretreated coal was sprinkled on the surface of microorganisms and present the situation of being liquefied. If microbes can liquefy coal into black drops or liquefied product dye these microorganisms could be used for further liquefaction.

\section{Culture of Single White Rot Fungi and Coal Liquefaction}

The coal liquefaction fungus medium was DOX medium consisting of $\left(\mathrm{L}^{-1}\right)$ : Sodium glutamate $2.0 \mathrm{~g}, \mathrm{NaNO}_{3} 3.0 \mathrm{~g}$, Glucose $10.0 \mathrm{~g}, \mathrm{~K}_{2} \mathrm{HPO}_{4} 2.0 \mathrm{~g}, \mathrm{MgSO}_{4} \cdot 7 \mathrm{H}_{2} \mathrm{O} 0.5 \mathrm{~g}$, and $\mathrm{KCl} 0.5 \mathrm{~g}$.

Puncturing a well-developed place on PDA medium with a 4 $\mathrm{mm}$ bore punch, the inoculated needles were used to separate and transfer the cake to an Erlenmeyer flask containing DOX liquid medium, and this was then cultivated in an incubator at a rotation speed of $120 \mathrm{rpm}$ at $28^{\circ} \mathrm{C}$. When the strain grew vigorously in the DOX medium, $0.50 \mathrm{~g}$ of pretreated Zhaotong lignite was added to the medium and the culture was continued in the incubator.

In order to determine the liquefaction effect of strain on lignite, $1 \mathrm{~mL}$ liquid was removed periodically from the cone bottle and characterized by $450 \mathrm{~nm}$ absorbance; as much research has shown, the greater the absorbance is the better the effect of lignite liquefaction (Shin et al., 1995; Hofrichter and Fritsche, 1997; Gokcay et al., 2001; Shi et al., 2013).

\section{Culture of Mixed White Rot Fungi and Coal Liquefaction}

Through the comparison of liquefaction and the enzyme activity of single strains, the researchers selected mycelium strains with higher enzyme activity and blended the two for mixed cultivation. For the cultivation of a single strain, two identical mycelium cakes were picked out; for the mixed strains, two mycelium cakes with different strains were inserted into the same Erlenmeyer flask. Then, the inoculated flasks were placed in a constant temperature shaker at $28^{\circ} \mathrm{C}$. The culture solution was periodically taken out as a crude enzyme solution, and the enzyme activity was measured. After a certain period of time, $0.5 \mathrm{~g}$ of lignite was added, and the liquefaction continued. In addition to this, the absorbance at $450 \mathrm{~nm}$ and the enzyme activity were measured periodically and compared with the liquefaction of a single strain.

\section{Determination of the Activity of Lignin Peroxidase}

A $1 \mathrm{~mL}$ reaction solution plus $0.2 \mathrm{~mL}$ resveratrol solution $(10$ $\mathrm{mmol} / \mathrm{l}), 0.4 \mathrm{~mL}$ tartrate buffer $(250 \mathrm{mmol} / \mathrm{L}, \mathrm{pH} 3.0), 0.4 \mathrm{~mL}$ culture solution or dilution, and $20 \mu \mathrm{L}$ hydrogen peroxide solution $(20 \mathrm{mmol} / \mathrm{L})$ were selected. After a few minutes of reaction in a $10^{\circ} \mathrm{C}$ water bath, the change of absorbance value at the wavelength of $310 \mathrm{~nm}$ was measured. The formation of 1 $\mu \mathrm{mol}$ of veratraldehyde by oxidation of resveratrol per minute was defined as an enzyme activity unit, as shown in Equation (1):

$$
\operatorname{Enzyme} \operatorname{activity}(\mathrm{U} / \mathrm{L})=\frac{\mathrm{N} \times \Delta \mathrm{OD}_{310} \times 10^{6}}{9300 \times 3}
$$

where $\mathrm{N}$ is the dilution multiple, $\Delta \mathrm{OD}_{310}$ is the increase in absorbance of the reaction solution at $310 \mathrm{~nm}$ in $3 \mathrm{~min}$, and 9,300 is the molar absorptivity $\left(\mathrm{L} \mathrm{mol}^{-1} \mathrm{~cm}^{-1}\right)$ of the oxidation state of resveratrol.

\section{Macromolecular Structure Analysis of Lignite and Its Liquefaction Products}

In order to study the catalysis of lignin peroxidase in the liquefaction of lignite, ${ }^{13} \mathrm{C}$ NMR analysis was performed on the lignite and the liquefaction products obtained after liquefaction by a Bruker AVANCE III $400 \mathrm{WB}$ Fourier transform NMR spectrometer. The static magnetic field was $\mathrm{B}_{0}=9.4 \mathrm{~T}$, and the corresponding proton and ${ }^{13} \mathrm{C}$ resonance frequencies were 400.1 and $100.6 \mathrm{MHz}$, respectively. The spectrometer used a $7 \mathrm{~mm}$ diameter $\mathrm{ZrO}_{2}$ rotor with a magic angle rotation speed of $4 \mathrm{kHz}$ and a transfer of $54.7^{\circ}$. By using CP/MAS/TOSS nuclear magnetic resonance technology, the cross-polarization contact time was $1 \mathrm{~ms}$ and the cycle time was $2 \mathrm{~s}$. The ${ }^{13} \mathrm{C}$ chemical shift $\delta$ was referenced to hexamethylbenzene of high-field magnetic resonance (17.17 ppm).

Eight lignite macromolecular structural parameters and their liquefaction products were calculated in order to calculate the change of the connection form of various carbons before and after liquefaction (Solum et al., 1989). The ratio of aliphatic carbon $\left(f_{\mathrm{al}}, \delta<100 \mathrm{ppm}\right)$, aromatic carbon $\left(f_{\mathrm{a}}, \delta>100 \mathrm{ppm}\right)$, phenol or aryl ether carbon $\left(f_{\mathrm{a}}^{\mathrm{P}}, \delta=150-165 \mathrm{ppm}\right)$, carbonyl carbon ratio $\left(f_{\mathrm{a}}^{\mathrm{C}}, \delta>165 \mathrm{ppm}\right)$, adeps-methyl or arylmethyl $\left(f_{\mathrm{al}}^{*}\right.$, $\delta=0-22 \mathrm{ppm})$, substituted aromatic carbon in the aromatic $\operatorname{ring}\left(f_{\mathrm{a}}^{\mathrm{S}}, \delta=135-150 \mathrm{ppm}\right)$, quaternary carbon, aliphatic carbon attached to oxygen atom $\left(f_{\mathrm{al}}^{\mathrm{O}}, \delta=50-95 \mathrm{ppm}\right)$, and $\mathrm{CH}$ or $\mathrm{CH}_{2}$ $\left(f_{\mathrm{al}}^{\mathrm{H}}, \delta=22-50 \mathrm{ppm}\right)$ can be calculated based on the absorption peak area of the chemical shift, as shown in Equations (2-9).

$$
\begin{array}{r}
f_{a}=\frac{I_{100-210}}{I_{0-210}} \\
f_{a l}=1-f_{a} \\
f_{a}^{C}=f_{a} \frac{I_{165-210}}{I_{100-210}} \\
f_{a}^{\mathrm{P}}=\frac{I_{150-165}}{I_{0-210}} \\
f_{\mathrm{a}}^{\mathrm{S}}=\frac{I_{135-150}}{I_{0-210}} \\
f_{a l}^{*}=\frac{I_{0-22}}{I_{0-210}} \\
f_{a l}^{C}=\frac{I_{50-95}}{I_{0-210}} \\
f_{\mathrm{al}}^{\mathrm{H}}=\frac{I_{22-50}}{I_{0-210}}
\end{array}
$$




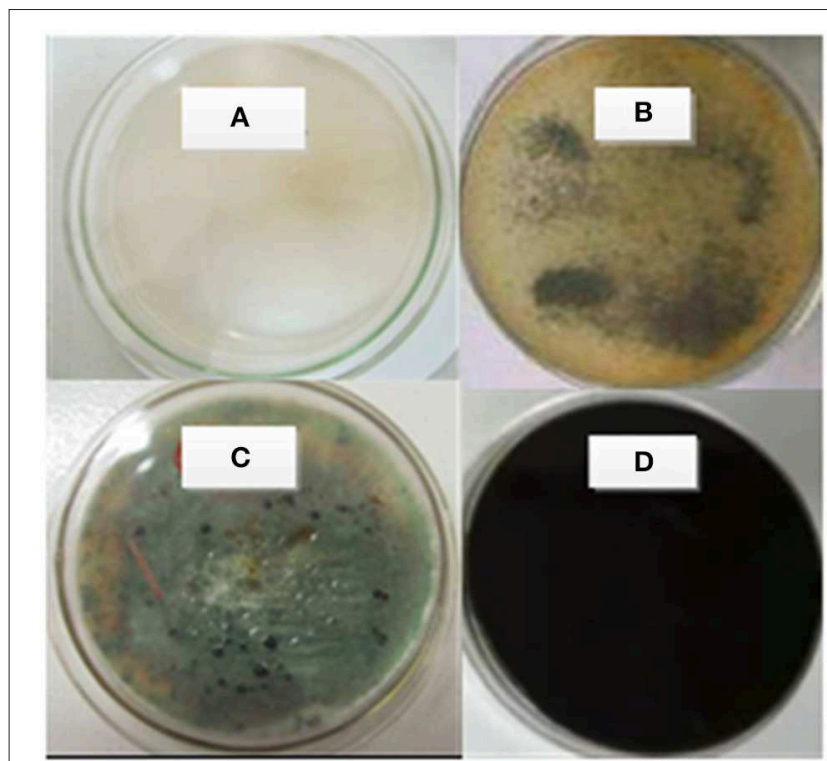

FIGURE 1 | Effect of White Rot Fungi on Liquefaction of Zhaotong Lignite. (A) Strains + DOX culture; (B) Zhaotong lignite + DOX culture; (C) strains + DOX culture + Zhaotong lignite (upper side); (D) strains + DOX culture + Zhaotong lignite (back side).

\section{EXPERIMENTAL RESULTS AND ANALYSIS}

\section{Strain Screening}

Thirty-four fungi were screened and continuously purified from soil, pit water, and decay wood, and then used for lignite liquefaction. There are 13 fungi with significant liquefaction capacity: ZTW107, GL301, ZX092, ZT201, ZT053, ZT101, ZTW07, ZTL153, SL203, ZTM23, ZTL307, ZTL205, and SL112. These strains can liquefy Zhaotong lignite, and the liquefaction effect of lignite in one strain is shown in Figure 1, from which it can be found that $\mathrm{a}$ and $\mathrm{b}$ are the control groups. In $\mathrm{c}$, we can see that the fungi have liquefied the Zhaotong lignite into black droplets, and in $\mathrm{d}$ we can see that the resulting black liquefaction products have dyed the DOX black.

\section{Effect of Single White Rot Fungi on Lignite Liquefaction}

The 13 fungi screened above, together with the two typical coal liquefaction fungi purchased, T. versicolor and S. commune, were inoculated to DOX medium. On the second day, Zhaotong lignite was added and continued to cultivate, and the extracellular LiP activity was also measured on the ninth day. The result is shown in Figure 2, which reveals that there is a large difference in the activity of LiP enzymes produced by different fungi, with the lowest being ZTW107, which is 1.94 U/L. Five strains with highest LiP enzyme activity are SL203, T. versicolor, ZTL153, S. commune, and ZTW07, that is, 51.2, 56.8, 46.3, 64.0, and 25.2 $\mathrm{U} / \mathrm{L}$, respectively.

At the same time, the absorbance at $450 \mathrm{~nm}$ was measured. Taking LiP enzyme activity as abscissa and absorbance at $450 \mathrm{~nm}$ as ordinate, and the relationship between the liquefaction effect
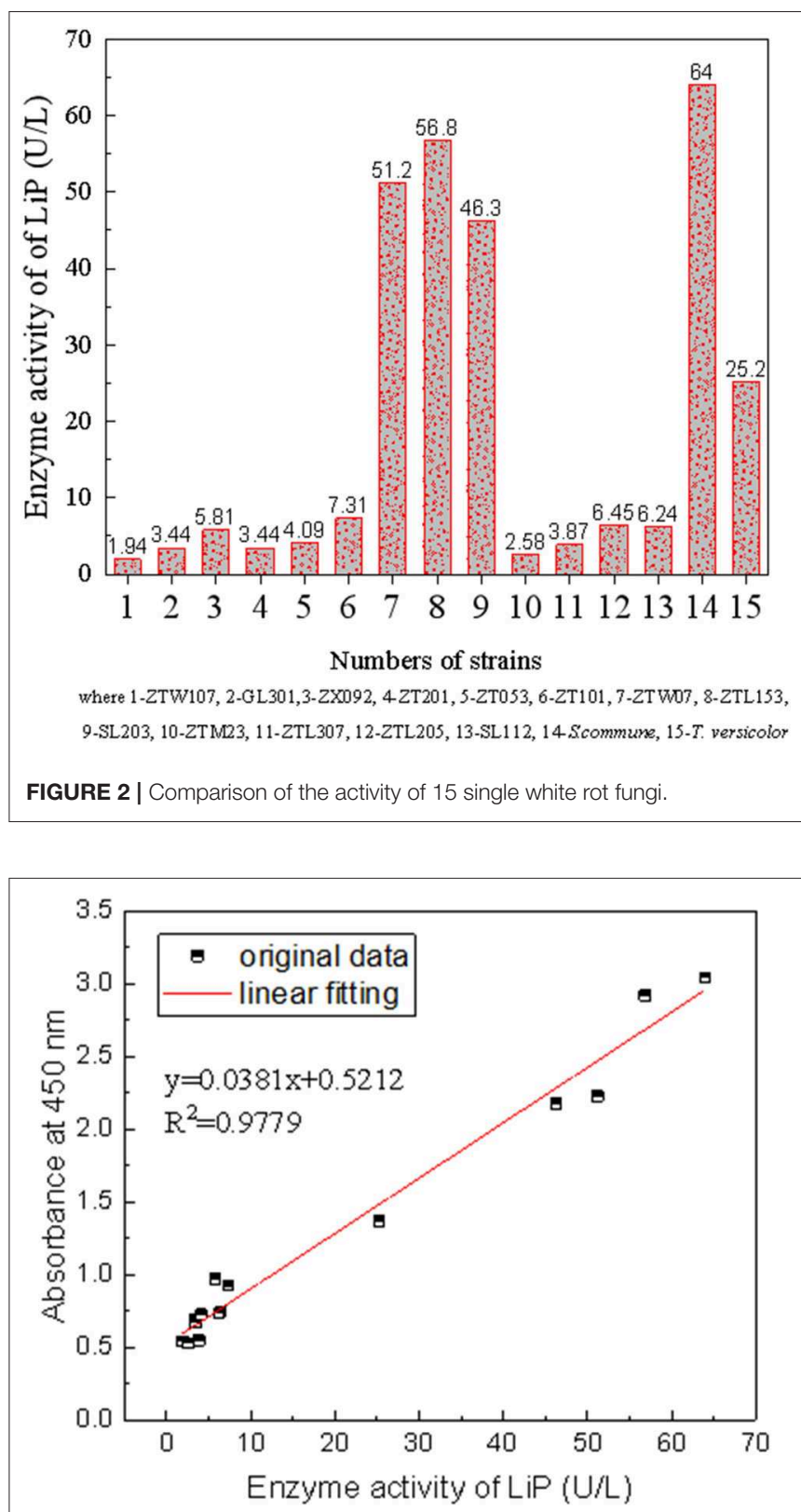

FIGURE 3 | The relationship between the effect of a single strain and the activity of the LiP enzyme.

and LiP enzyme activity is plotted and shown in Figure 3. From the figure, we can see that there is a clear linear relationship between the liquefaction effect (A450) and LiP activity. $R^{2}$ is 0.9779 , and $y$ (liquefaction effect $)=0.0381 \times($ LiP activity $)+$ 0.5212 . The result shows that LiP plays an important role in the Zhaotong lignite liquefaction.

\section{Effect of Mixed White Rot Fungi on Lignite Liquefaction}

The five fungi with the highest LiP activity and liquefaction effects from Figure 2, strains ZTW07, ZTL153, SL203, S. commune, 


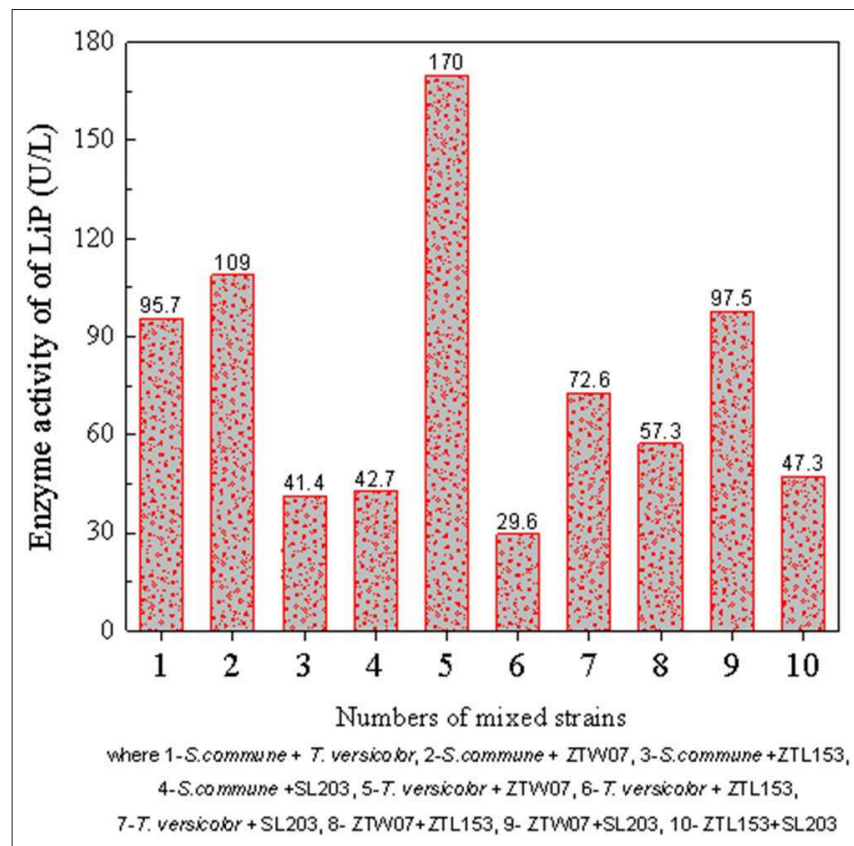

FIGURE 4 | Comparison of the activity of mixed strains on day 9

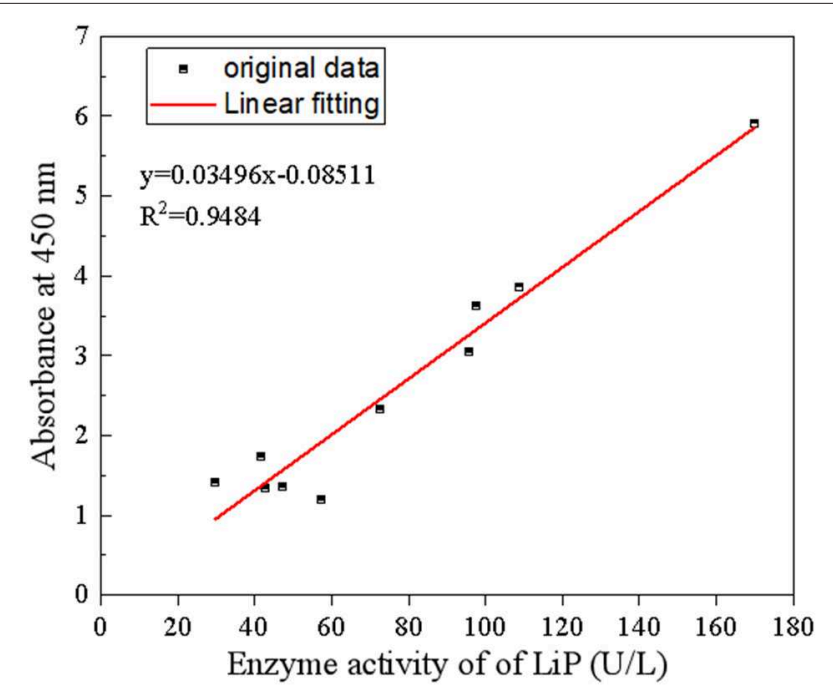

FIGURE 5 | Relationship between LiP activity and the liquefaction effect of mixed white rot fungi.

and T. versicolor, were selected, and two strains of the five were blended for mixed strains culture. The LiP activity of the mixed strains on the ninth day is shown in Figure 4, and the relationship between LiP activity and the liquefaction effect $(\mathrm{A} 450 \mathrm{~nm})$ is shown in Figure 5. As shown in Figure 5, lignite liquefaction (absorbance at $450 \mathrm{~nm}$ ) still has a high linear relationship with LiP in mixed strains. $y($ absrobance at $450 \mathrm{~nm})=0.03496 \times$ (activity of Lip) -0.08511 and $R^{2}$ is 0.9484 .

Comparing Figure 2 and Figure 4, we can see these four mixed strains, which are combination 1 (S. commune $+T$. versicolor), combination 2 (T. versicolor + ZTW07), combination 5 (T. versicolor + SL203), and combination 9 (ZTW07 + SL203), have much higher LiP activity than a single strain. In order to compare the enzymatic activity of single strains and mixed strains, the activity of LiP needs to be measured before the addition of lignite on day 0 as well as on day 3rd, 6th, and 9th day after the addition of lignite. The change of enzyme activity was plotted, and the results are shown in Figure 6.

Figure 6A shows that the mixed strains culture of S. commune and $T$. versicolor both have a synergistic effect on the liquefaction of lignite. The highest LiP activity of S. commune and T. versicolor were 63.978 and $25.215 \mathrm{U} / \mathrm{L}$, respectively, while the highest activity after mixing was $95.663 \mathrm{U} / \mathrm{L}$. The combinations of $T$. versicolor and ZTW07 (Figure 6B), T. versicolor and SL203 (Figure 6C), and ZTW07 and SL203 (Figure 6D) also had strong synergy in secreting LiP enzymes. The highest enzymatic activity of the single strain, T. versicolor and ZTW07, was 25.215 and $56.802 \mathrm{U} / \mathrm{L}$, respectively, while the highest activity after mixing was $170.00 \mathrm{U} / \mathrm{L}$, which was 6.7 and 3.0 times that of the single strain. The highest enzymatic activity of T. versicolor and SL203 was 1.6 and 2.9 times that of the single strain, respectively. The highest enzymatic activity of ZTW07 after mixing and SL203 after mixing was 1.9 and 2.1 times that of the single strain, respectively.

Other combinations of mixed strains had no significant effect on LiP secretion, and this was even lower than that of a single strain, as shown in Figure 4 (number 3, 4, 6, 7, 8, and 10).

After considering all the combinations, $T$. versicolor and ZTW07 have the highest LiP activity, which reached $170.00 \mathrm{U} / \mathrm{L}$ on the 9th day of coal liquefaction.

\section{Comparison of Liquefaction of Lignite by Single Strains and Mixed Strains}

Table 1 shows a comparison between the main indicators in the liquefaction of lignite by single strains and mixed strains. It can be clearly seen that the highest lignin peroxidase activity of the mixed strains was $170.00 \mathrm{U} / \mathrm{L}$, and the average activity was $76.28 \mathrm{U} / \mathrm{L}$, while the single strain was only 63.98 and $19.24 \mathrm{U} / \mathrm{L}$. Similarly, the liquefaction effect (absorbance at $450 \mathrm{~nm}$ ) of the mixed strains has a maximum value of 5.91 and an average value of 2.58, whereas single strains had only 3.08 and 1.25 . Therefore, the liquefaction of mixed strains is an effective way to improve the liquefaction efficiency of lignite, and lignin peroxidase plays a key role in this.

\section{${ }^{13} \mathrm{C}$ NMR Analysis of Macromolecules Structure of Lignite and Its Liquefaction Products}

This section has analyzed the macromolecular structure of lignite before liquefaction and its liquefied product. Since carbon is the main skeleton element of coal macromolecules, ${ }^{13} \mathrm{C}$ NMR was used for analysis in this study. The results are shown in Figure 7. Table 2 lists the corresponding carbon connections represented by the peaks in the spectrum. From Figure 7 and Table 2, the main forms of carbon in lignite are $-\mathrm{CH}_{3}(20.3,17.9 \mathrm{ppm})$, aromatic ring $(128.9,134.0 \mathrm{ppm})$, followed by $-\mathrm{CH}_{2}-(42.8 \mathrm{ppm})$ and $-\mathrm{COOH} / \mathrm{R}$ (162.5 and $178.3 \mathrm{ppm})$. On the other hand, for 

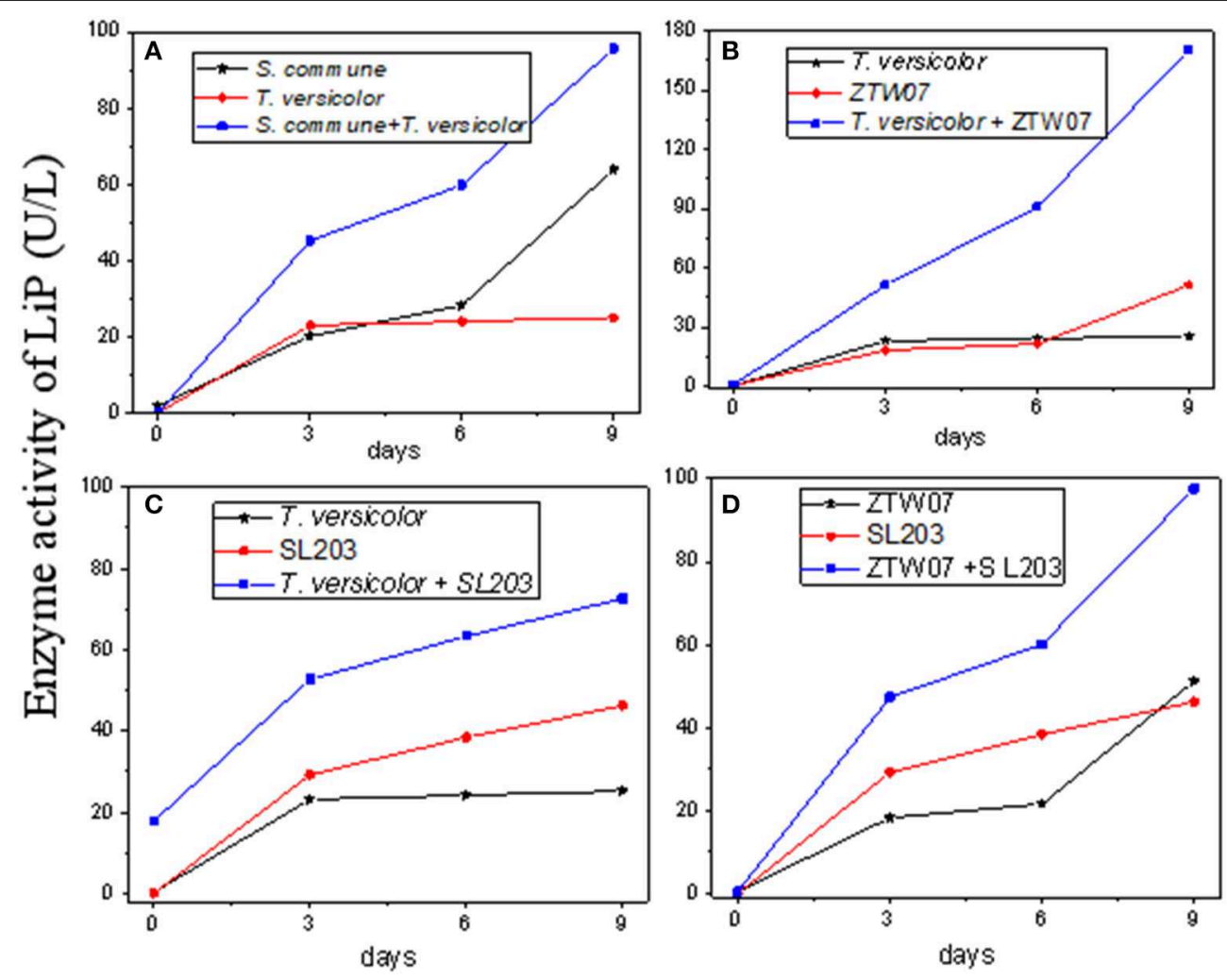

FIGURE 6 | Comparison of lignin peroxidases in different combinations of mixed strains. (A) mixture of S. commune and T. versicolor, (B) mixture of T. versicolor and ZTW 07, (C) mixture of T. versicolor and SL203, (D) mixture of ZTW07 and SL203.

TABLE 1 | Comparison of liquefaction of lignite by single strains and mixed strains.

\begin{tabular}{lcccccccc}
\hline & \multicolumn{3}{c}{ Activity of LiP } & & \multicolumn{3}{c}{ Absorbance at $\mathbf{4 5 0} \mathbf{~ n m}$} \\
\cline { 2 - 3 } \cline { 6 - 8 } & & Maximum & Minimum & Average & & Maximum & Minimum & Average \\
\hline Single strain & 63.98 & 1.94 & 19.24 & & 3.08 & 0.53 & 1.25 \\
Mixed strains & 170 & 29.65 & 76.28 & & 5.91 & 1.2 & 2.58 \\
\hline
\end{tabular}

liquefied products, the predominant form of $\mathrm{C}$ is $=\mathrm{C}-\mathrm{O}-(81.5$ ppm), followed by aromatic and heterocyclic C (142.1, 151.1 ppm), $-\mathrm{CH}_{2}-(37.3 \mathrm{ppm})$, and $-\mathrm{COOH}$ (187.1 ppm).

According to the spectral information in Figure 7, the macromolecular structure parameters of lignite and liquefaction products can be calculated by calculating the spectral area of different chemical shifts using the origin. The results are listed in Table 3. It is revealed that the aromatic carbon rate $f_{\mathrm{a}}$ of lignite is $56.52 \%$, which shows that the coalification degree of the lignite and the degree of its aromatic ring condensation are both low, so it is a typical low-rank coal. The proportion of carbonyl carbon $\left(f_{\mathrm{a}}^{\mathrm{C}}\right)$, and oxygen-linked aliphatic carbon $\left(f_{\mathrm{al}}^{\mathrm{O}}\right)$ in total carbon was high, and they were 20.48 and $23.95 \%$, respectively. In addition, the proportion of phenol or aryl ether carbon $\left(f_{\mathrm{a}}^{\mathrm{P}}\right)$ was $7.55 \%$. The proportion of these three types of $\mathrm{C}$ connected to $\mathrm{O}$ was $51.98 \%$ in total, indicating that the lignite contained a high degree

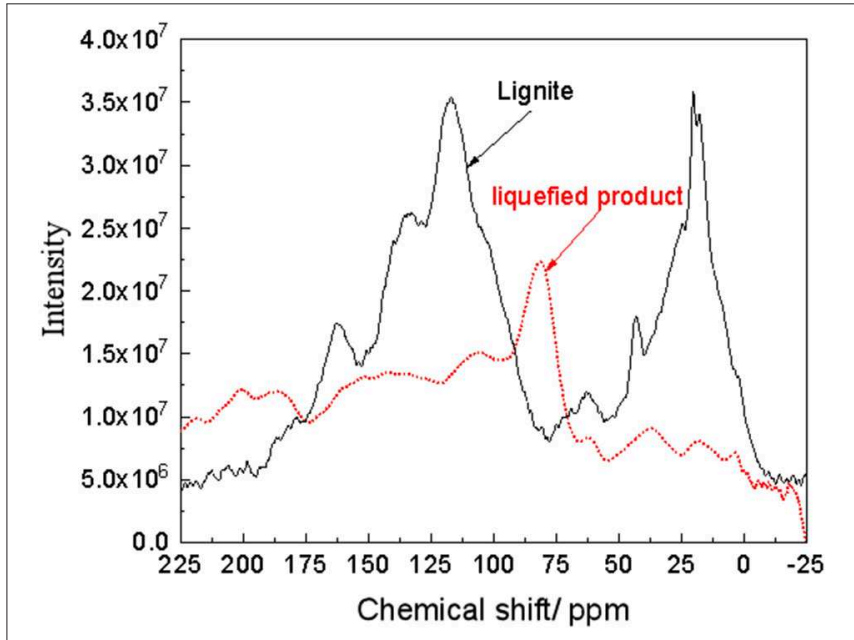

FIGURE $7 \mid{ }^{13} \mathrm{C}$ NMR spectra of coal and liquefaction products.

of oxidation. The carbon content in the methyl carbon $\left(f_{\mathrm{al}}^{*}\right)$ and $\mathrm{CH} / \mathrm{CH}_{2}$ was not high; they were 6.45 and $9.09 \%$, respectively, suggesting that the lignite had a short side chain length.

The parameters of macromolecules of liquefaction products were relatively close to those before liquefaction. The rate of 
TABLE 2 | 13C NMR peak assignment table.

\begin{tabular}{llll}
\hline & Lignite & \multicolumn{2}{c}{ Liquefied products } \\
\cline { 3 - 4 }$\delta / \mathbf{p p m}$ & Functional groups & $\delta / \mathbf{p p m}$ & Functional groups \\
\hline 212.4 & $>\mathrm{C}=\mathrm{O}$ & 218.3 & $>\mathrm{C}=\mathrm{O}$ \\
206 & $-\mathrm{CHO}$ or $>\mathrm{C}=\mathrm{O}$ & 200.6 & $-\mathrm{CHO}$ or $>\mathrm{C}=\mathrm{O}$ \\
198.2 & $-\mathrm{CHO}$ or $>\mathrm{C}=\mathrm{O}$ & 187.1 & $-\mathrm{COOH}$ \\
182.1 & $-\mathrm{COOH}$ & 151.1 & $>\mathrm{C}=\mathrm{N}$ or aromatic $\mathrm{C}$ \\
178.3 & $-\mathrm{COOH}$ or $-\mathrm{COOR}$ & 142.1 & $-\mathrm{C}=\mathrm{C}-$ in heterocycle \\
162.5 & $-\mathrm{COOH}$ or $-\mathrm{COOR}$ & 106.5 & Aromatic $\mathrm{C}$ \\
134 & Aromatic $\mathrm{C}$ & 81.5 & $=\mathrm{C}-\mathrm{O}-$ \\
128.9 & Aromatic $\mathrm{C}$ & 61.5 & $-\mathrm{CH}-\mathrm{O}-,>\mathrm{CH}-\mathrm{O}-$ \\
80.7 & $=\mathrm{C}-\mathrm{O}-$ & 37.3 & $-\mathrm{CH}-$ \\
63 & $-\mathrm{CH}_{2}-\mathrm{O}-,>\mathrm{CH}-\mathrm{O}-$ & 18 & 0 \\
42.8 & $-\mathrm{CH}_{2}-\mathrm{O}-$ & 3.2 & $\mathrm{C}-\mathrm{C}$ in saturated hydrocarbon \\
20.3 & 0 & & \\
17.9 & 0 & & \\
\hline
\end{tabular}

TABLE 3 | Structure parameters of Zhaotong lignite and liquefied product according to ${ }^{13} \mathrm{C}$ NMR.

\begin{tabular}{lcccccccc}
\hline Parameter & $\boldsymbol{f}_{\mathrm{a}}$ & $\boldsymbol{f}_{\mathrm{a}}^{\mathbf{C}}$ & $\boldsymbol{f}_{\mathrm{a}}^{\mathrm{P}}$ & $\boldsymbol{f}_{\mathrm{a}}^{\mathbf{S}}$ & $\boldsymbol{f}_{\mathrm{al}}$ & $\boldsymbol{f}_{\mathrm{al}}^{\mathrm{H}}$ & $\boldsymbol{f}_{\mathrm{al}}^{*}$ & $\boldsymbol{f}_{\mathrm{al}}^{\mathrm{O}}$ \\
\hline $\begin{array}{l}\text { Zhaotong } \\
\text { Lignite/\% }\end{array}$ & 56.52 & 20.48 & 7.55 & 8.09 & 43.38 & 9.09 & 6.45 & 23.95 \\
$\begin{array}{l}\text { Liquefied } \\
\text { product/\% }\end{array}$ & 54.41 & 19.82 & 8.42 & 7.89 & 45.59 & 8.85 & 6.28 & 24.33 \\
\end{tabular}

aromatic carbon $\left(f_{\mathrm{a}}\right)$ decreased to $54.41 \%$, showing that the ring opening reaction took place under the catalysis of LiP, and some aromatic rings of coal macromolecules were opened. On the other hand, the relative content of phenol or aryl ether carbon $\left(f_{\mathrm{a}}^{\mathrm{P}}\right)$ and oxygen-linked fatty carbon $\left(f_{\mathrm{al}}^{\mathrm{O}}\right)$ increased by 0.87 and $0.38 \%$, respectively, indicating that an oxidized reaction occurred while the aromatic ring was opened. Additionally, the methyl and methylene carbons in the side chains $\left(f_{\mathrm{al}}^{\mathrm{H}}\right.$ and $f_{\text {al }}^{*}$ ) also decreased, which indicates that LiP also catalyzed the demethylation reaction.

\section{CONCLUSION}

In this research, 34 strains of fungi were screened and isolated from nature; of these, 13 strains had the ability to liquefy Zhaotong lignite. The liquefaction of Zhaotong lignite was carried out using the 13 strains of fungi together with two white rot fungi that were purchased. By comparing the activity of lignin peroxidase and the absorbance at $450 \mathrm{~nm}$, several conclusions were made.

(1) There existed a good linear relationship between lignin liquefaction $(\mathrm{A} 450 \mathrm{~nm})$ and lignin peroxidase (LiP) activity and $R^{2}$ is 0.9779 , which proved that lignin peroxidase played a key role in lignite liquefaction.
(2) In the process of the liquefaction of Zhaotong lignite by 15 single strains, the activity of the LiP enzyme fluctuated from 1.94 to $63.98 \mathrm{U} / \mathrm{L}$ with an average value of $19.24 \mathrm{U} / \mathrm{L}$. The absorbance of A450 nm fluctuated from 0.53 to 3.08 with an average value of 1.25 .

(3) On the condition of a single strains culture, when the five fungi with the highest LiP activity were cultured in combination, the activity of the LiP enzyme fluctuated between 29.65 and $170.00 \mathrm{U} / \mathrm{L}$ with an average value of 76.28 $\mathrm{U} / \mathrm{L}$. The absorbance of A450 $\mathrm{nm}$ ranged from 1.20 to 5.91 with an average value of 2.58 .

(4) Among the 10 combinations of mixed strains, there were four combinations of white rot fungi producing LiP that had an obvious synergistic effect, and the LiP activity of mixed strains was 1.5-6.7 times that of a single strain. Among them, the combination of T. versicolor and ZTW07 had the highest activity, and the LiP activity reached 170.00 $\mathrm{U} / \mathrm{L}$ on the ninth day of liquefaction, while the activity of LiP on T. versicolor and ZTW07 was only 25.22 and 56.80 $\mathrm{U} / \mathrm{L}$, respectively.

(5) Through ${ }^{13} \mathrm{C}$ NMR analysis, it was found that the aromatic carbon ratio $f_{\mathrm{a}}$ of lignite before liquefaction was 0.565 , and the aromatic carbon ratio of the product obtained after liquefaction was 0.544 , which indicated that the lignite underwent a ring opening reaction under the catalysis of LiP. In addition, the relative contents of phenol or aryl ether carbon $\left(f_{\mathrm{a}}^{\mathrm{P}}\right)$ and oxygen-linked aliphatic carbon $\left(f_{\mathrm{al}}^{\mathrm{O}}\right)$ increased by 0.87 and $0.38 \%$, respectively, and this indicated that a certain oxidation reaction occurred.

\section{DATA AVAILABILITY STATEMENT}

The raw data supporting the conclusions of this manuscript will be made available by the authors, without undue reservation, to any qualified researcher.

\section{AUTHOR CONTRIBUTIONS}

KS participated in experimental design and data processing. JW participated in experimental design and paper writing.

\section{FUNDING}

This research was financially supported by the National Natural Science Foundation of China (No. 51504134), Key Supported Discipline of Guizhou Provence (Qian Xuewei $\mathrm{He} \mathrm{Zi}$ ZDXK[2016]24), the 2011 Collaborative Innovation Center of Guizhou Province (Qian Jiao he xietongchuangxin zi [2016]02), the Liupanshui Normal University Creative Team (LPSSYKJTD201401), the Liupanshui Normal University High Level Talent Opening Foundation (LPSSYKYJJ201402), and the Guizhou Institutions of Higher Education innovation team (Qian Jiao he rencaituandui zi [2015]69). 


\section{REFERENCES}

Asgher, M., Shah, S. A. H., Ali, M., and Legge, R. L. (2006). Decolonization of some reactive textile yes by white rotfungi isolated in Pakistan. World J. Microbiol. Biotechnol. 122, 89-96. doi: 10.1007/s11274-005-5743-6

Barbara, B. (2017). Change of the petrographic composition of lignite during the ex-situ lignite gasification. Fuel 206, 219-229. doi: 10.1016/j.fuel.2017.06.006

Barrasa, J. M., Blanco, M. N., Esteve-Raventós, F., Altés, A., Checa, J., Martínez, A. T., et al. (2014). Wood and humus decay strategies by white-rot basidiomycetes correlate with two different dye decolorization and enzyme secretion patterns on agar plates. Fungal Genet. Biol. 72, 106-114. doi: 10.1016/j.fgb.2014. 03.007

BP Statistical Review (2017). BP Statistical Review of World Energy [Online]. Available online at: https://www.bp.com/ (accessed April 21, 2018).

Bublitz, F., Günther, T., and Fritsche, W. (1994). Screening of fungi for the biological modification of hard coal and coal derivatives. Fuel Process. Technol. 40, 347-354. doi: 10.1016/0378-3820(94)90157-0

Choudhary, S., Thakur, A., Gupta, A., and Amebkar S. B. (2016). Review of different technologies for coal liuefaction. Int Res. J. Eng. Technol. 3, 2704-2708.

Chuanren, D., Zhu, L., and Yao, Y. (2009). Comparative studies on lignin degradation enzymes produced by three species of white-rot fungi and combination of the strains. Mycosystema 28, 577-583. doi: 10.13346/j.mycosystema.2009.04.002

Cohen, M. S., and Gabriele, P. D. (1982). Degradation of coal by the fungi polyporus versicolor and Poria monticola. Appl. Environ. Microbiol. 44, 23-27.

David, Y., Baylon, M. G., Pamidimarri, S. D., Baritugo, K. A., Chae, C. G., Kim, Y. J., et al. (2017). Screening of microorganisms able to degrade low-rank coal in aerobic conditions: potential coal biosolubilization mediators from coal to biochemicals. Biotechnol. Bioprocess Eng. 22, 178-185. doi: 10.1007/s12257-016-0263-9

Gokcay, C. F., Kolankaya, N., and Dilek, F. B. (2001). Microbial solubilization of lignites. Fuel 80, 1421-1433. doi: 10.1016/S0016-2361(01)00010-2

Haemmerli, S. D., Leisola, M. S., Sanglard, D., and Fiechter, A. (1986). Oxidation of benzo (a) pyrene by extracellular ligninases of Phanerochaete chrysosporium. J. Biol. Chem. 261, 6900-6903.

Hammel, K., Jensen, K. A., Mozuch, M. D., Landucci, L. L., Tien, M., and Pease, E. A. (1993). Ligninolysis by a purified lignin peroxidase. J. Biol. Chem. 268:12274-12281.

Hammel, K. E., Kalyanaraman, B., and Kirk, T. K. (1986). Oxidation of polycycli caromatic hydrocarbons and dibenzo [p]-dioxins by Phanerochaete chrysosporium ligninase. J. Biol. Chem. 261, 16948-16952.

Han, F., Meng, A., Li, Q., and Zhang, Y. (2016). Thermal decomposition and evolved gas analysis (TG-MS) of lignite coals from Southwest China. J. Energy Inst. 89, 94-100. doi: 10.1016/j.joei.2015.01.007

Hayatsu, R., Winans, R. E., McBeth, R. L., Scott, R. G., Moore, L. P., and Studier, M. H. (1979). Lignin-like polymers in coals. Nature 278, 41-43. doi: $10.1038 / 278041 \mathrm{a} 0$

Hofrichter, M., and Fritsche, W. (1997). Depolymerization of low-rank coal by extracellular fungal enzyme systems. II. The ligninolytic enzymes of the coal-humic-acid-depolymerizing fungus Nematoloma frowardii b19. Appl. Microbiol. Biotechnol. 47, 419-424. doi: 10.1007/s002530050950

Hölker, U., Ludwig, S., Scheel, T., and Höfer, M. (1999). Mechanisms of coal solubilization by the deuteromycetes Trichoderma atroviride and Fusarium oxysporum. Appl. Microbiol. Biotechnol. 52, 57-59. doi: 10.1007/s002530051486

Jiang, F., Li, Z., Lv, Z., Gao, T., Yang, J., Qin, Z., et al. (2013). The biosolubilization of lignite by Bacillus sp. Y7 and characterization of the soluble products. Fuel 103, 639-645. doi: 10.1016/j.fuel.2012.08.030

Luo, F., Zhong, Z., Liu, L., Igarashi, Y., Xie, D., and Li, N. (2017). Metabolomic differential analysis of interspecific interactions among white rot fungi Trametes versicolor, Dichomitus squalens and Pleurotus ostreatus. Sci. Rep. 7, 1-11. doi: 10.1038/s41598-017-05669-3

Ma, K., and Ruan, Z. (2015). Production of a lignocellulolytic enzyme system for simultaneous bio-delignification and saccharification of corn stover employing co-culture of fungi. Bioresour. Technol. 175, 586-593. doi: 10.1016/j.biortech.2014.10.161

Machnikowska, H., Pawelec, K., and Podgórska, A. (2002). Microbial degradation of low rank coals. Fuel Process. Technol. 77-78, 17-23. doi: 10.1016/S0378-3820(02)00064-4

Maka, A., Srivastava, V., Kllbane, J., and Akin, C. (1989). Biological solubilization of untreated north dakota lignite by a mixed bacterial and a mixed bacterial/fungal culture. Appl. Biochem. Biotechnol. 20-21, 715-729. doi: 10.1007/BF02936520

Mäkelä, M. R., Lundell, T., Hatakka, A., and Hildén, K. (2013). Effect of copper, nutrient nitrogen, and wood-supplement on the production of ligninmodifying enzymes by the white-rot fungus Phlebia radiate. Fungal Biol. 117, 62-70. doi: 10.1016/j.funbio.2012.11.006

Romanowska, I., Strzelecki, B., and Bielecki, S. (2015). Biosolubilization of Polish brown coal by Gordonia alkanivarans S7 and Bacillus mycoides NS 1020. Fuel Process. Technol. 131, 430-436. doi: 10.1016/j.fuproc.2014.12.019

Shi, K., Gui, X., Tao, X., Long, J., and Ji, Y. (2015). Macromolecular structure construction of fushun acid oxidized coal. Energy Fuels 29, 3566-3572. doi: $10.1021 /$ ef502859r

Shi, K. Y., Yin, S. D., Tao, X. X., Du, Y., He, H., Lv, Z. P., et al. (2013). Quantitative measurement of coal bio-solubilisation by ultraviolet- visible spectroscopy. Energy Sour. Part A Recov. Util. Environ. Effects 35, 1456-1462. doi: 10.1080/15567036.2010.521800

Shin, H. J., Lee, H. H., and Yang, J. W. (1995). Quantitative assay of biosolubilized coal by UV-spectrophotometry. Biotechnol. Tech. 9, 329-332. doi: $10.1007 / \mathrm{BF} 00638865$

Solum, M. S., Pugmire, R. J., and Grant, D. M. (1989). Carbon-13 solid-state NMR of Argonne-premium coals. Energy Fuels 3, 187-193. doi: 10.1021/ef00014a012

Sridevi, B., and Charya, M. A. S. (2011). Isolation, identification and screening of potential cellulase-free xylanase producing fungi. Afr. J. Biotechnol. 10, $4624-4630$

Tien, M., and Kirk, T. K. (1983). Lignin-degrading enzyme from the hymenomycete Phanerochaete chrysosporium burds. Science 221, 661-663. doi: 10.1126/science.221.4611.661

Tien, M., and Kirk, T. K. (1988). Lignin peroxidase of Phanerochaete chrysosporium. Methods Enzymol. 161, 238-249. doi: $10.1016 / 0076-6879(88) 61025-1$

Wen, Z., Liao, W., and Chen, S. (2005). Production of cellulase/ $\beta$-glucosidase by the mixed fungi culture Trichoderma reesei and Aspergillus phoenicis on dairy manure. Process Biochem. 40, 3087-3094. doi: 10.1016/j.procbio.2005. 03.044

Zhang, H., Zhang, B., and Bi, J. (2015). More efforts, more benefits: air pollutant control of coal-fired power plants in China. Energy 80, 1-9. doi: 10.1016/j.energy.2014.11.029

Conflict of Interest: The authors declare that the research was conducted in the absence of any commercial or financial relationships that could be construed as a potential conflict of interest.

Copyright $\odot 2019$ Shi and Wang. This is an open-access article distributed under the terms of the Creative Commons Attribution License (CC BY). The use, distribution or reproduction in other forums is permitted, provided the original author(s) and the copyright owner(s) are credited and that the original publication in this journal is cited, in accordance with accepted academic practice. No use, distribution or reproduction is permitted which does not comply with these terms. 